\title{
ANEURYSMAL DILATATION OF THE PULMONARY ARTERY
}

\author{
BY \\ K. D. WILKINSON
}

Received July 12, 1940

Aneurysmal dilatation of the pulmonary artery as a result of congenital defect is most commonly associated with a patent inter-auricular septum. This was not so in the present case, which seems to be worth record on account of its rarity.

The child in question appeared normal up to the age of ten years. The second child of healthy parents, she had bronchopneumonia at the age of six and catarrhal jaundice at nine, yet no cardiac defect was noted ; at ten years of age she was a spare child who weighed $42 \mathrm{lb}$. She was then admitted (in March 1936) to the Children's Hospital in Birmingham on account of breathlessness. This had only been noticed a short time during the winter of 1935-36, and her mother had also observed that her heart beat unusually forcibly and that her chest bulged forward and to the left side.

She was a healthy-looking girl with a fresh colour, quiet and friendly, and not excitable. The respiratory movement of the chest on the left side was limited. The heart was considerably enlarged, the apex being difficult to localize accurately, but the maximum impulse lay in the seventh left interspace, four inches from the midline. The area of cardiac pulsation was extensive, and the cardiac dulness extended up into the second left interspace in the mid-clavicular line.

The pulse was regular, 12 J per minute, and of poor volume. The blood pressure was $104 / 64 \mathrm{~mm}$.

At the apex the first sound was loud and appeared to be double, with a long systolic murmur. The second sound was loud and sharp. At the base both sounds were loud and clearly heard, and the first was followed by a long, blowing systolic murmur, maximal in the second left interspace, but audible over a wide area. The second sound was loud and there was no diastolic murmur.

During her stay in hospital she improved and the pulse rate fell to under 90 . The electrocardiogram showed a low voltage in lead $I$, with a tall $R_{2}$ and $R_{3}$ and a P-R interval of $0 \cdot 16$ of a second.

She was readmitted on April 29, 1939, because she had developed a spinal curvature-which was reported to be due to an early osteochondritis of the spine. She then weighed $50 \mathrm{lb}$. and had grown a good deal. The condition of the heart was as before: the systolic murmur was audible all over the chest; 
the second sound was remarkably loud everywhere; and there was no diastolic murmur. The sedimentation rate was 5 , and there was no evidence of infection. Radioscopy confirmed the great enlargement of the heart and showed some dilatation of the right pulmonary artery and an enormous shadow coming from the left pulmonary root (Fig. 1). This was also well shown in a partial oblique view with the patient turned slightly to her left (Fig. 2).

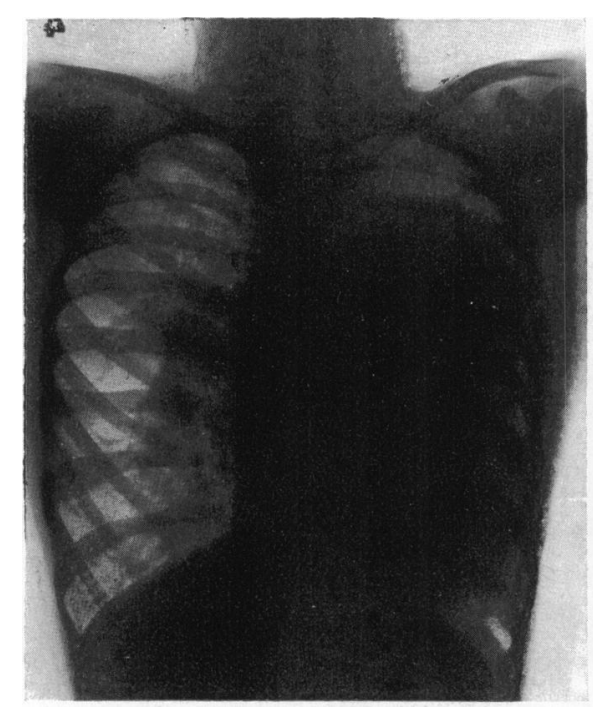

FIG. 1.-The direct antero-posterior radiogram (taken on April 14, 1939) shows gross enlargement of the pulmonary artery extending up to the second left interspace. The heart appears to lie a little to the left and the shadow almost completely fills the left chest. The pulmonary root on the right shows a large shadow, probably venous.

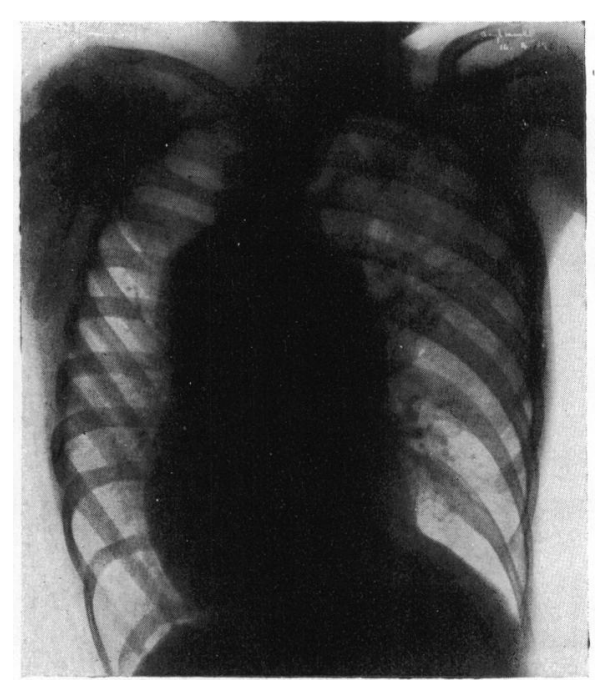

FIG. 2.-A slightly oblique radiogram, taken on April 14, 1939, shows the pulmonary distension and the cardiac enlargement below. The left lung is seen to be clear. The child had been slightly turned to the left, with the right shoulder forwards.

There had been no attack of syncope or cyanosis and no special complaint had been made about the heart. She was in hospital for a month and was provided with a spinal support, which she wore. After her discharge she continued to attend school, and appeared to enjoy normal health. She played no games and did not do physical exercises.

On September 5, 1939, when she came in from school at tea time, she said that she was tired and sat down. As she sat forward watching her mother transplanting a small plant, she suddenly put her hand to the left side of the chest and cried out "Oh, mother, the pain !" She fell forward and was " dead in a minute."

\section{Post-Mortem Findings}

There was definite bulging of the thorax to the left and a slight degree of kypho-scoliosis. The pericardium was tremendously distended with fluid blood, and the heart so enlarged that the left lung was considerably compressed. 
There were no pleural adhesions, but the left lung root was infiltrated with blood. The pulmonary artery was very large, the diameter being three inches, and its general appearance is well shown in Fig. 3. The effusion of clotted

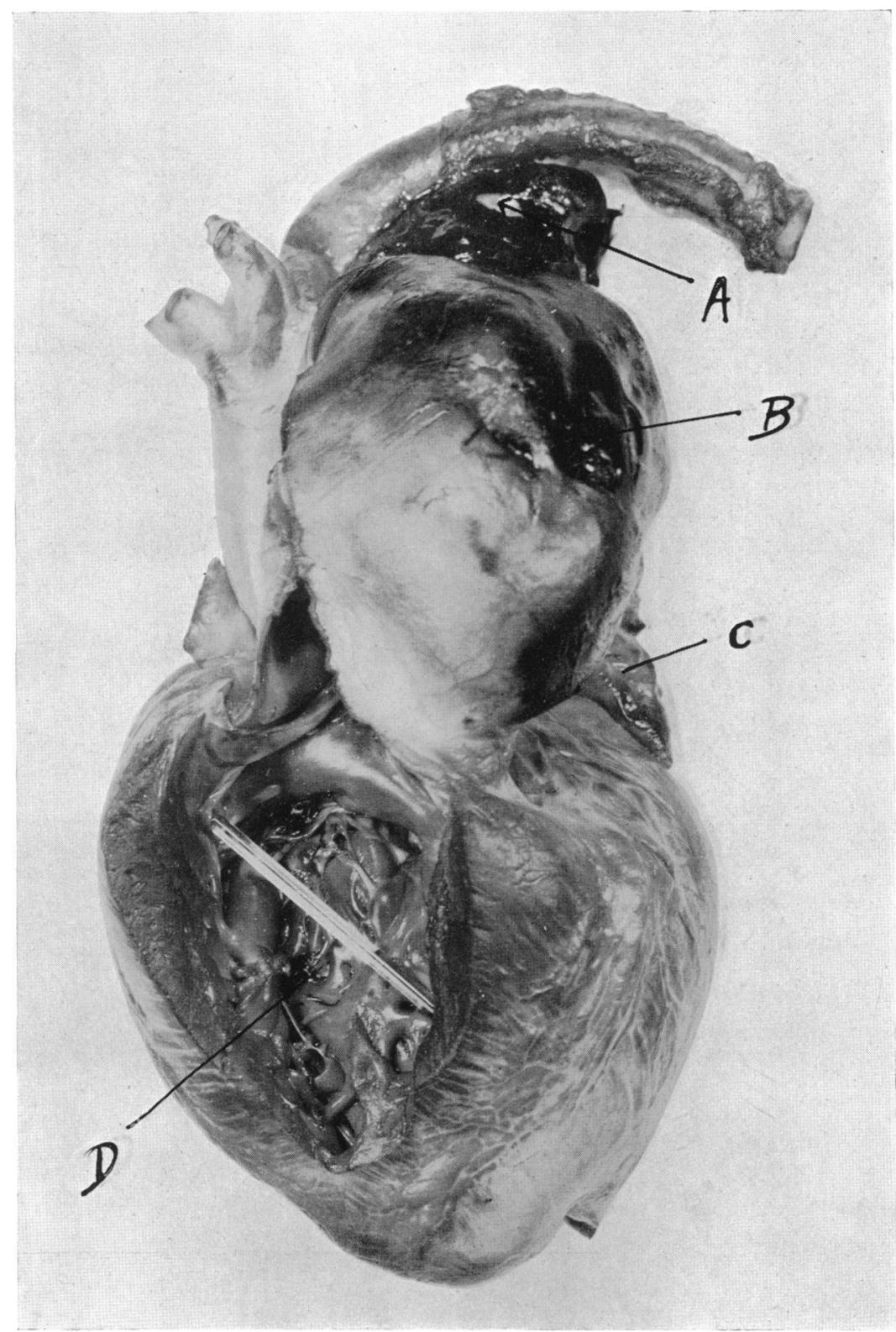

FIG. 3.-Photograph of the heart and great vessels post mortem, showing the great dilatation of the pulmonary artery.

(A) Clot of effused blood between the aorta and the aneurysm of the pulmonary artery.

(B) Effused blood in the wall of the aneurysm.

(C) Left auricle.

(D) Opened right ventricle. 


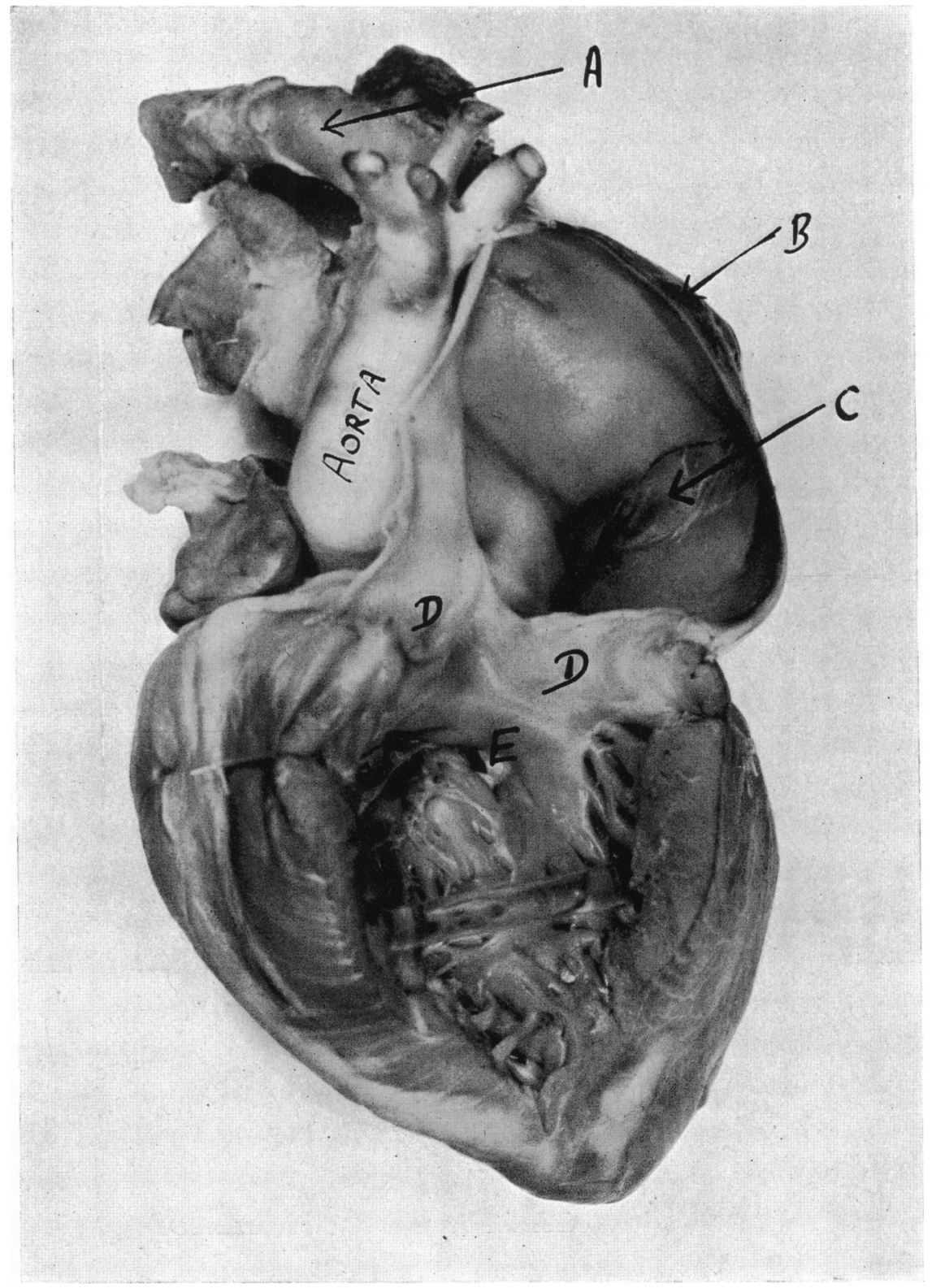

FIG. 4.--Photograph of the heart and great vessels post mortem. The right ventricle and the dilated pulmonary artery have been opened.

(A) Left pulmonary artery discoloured by effused blood.

(B) Effused blood in wall of dilated artery which has been opened.

(C) Site of rupture of the pulmonary artery.

(D) Two cusps of a bicuspid pulmonary valve.

(E) Just to the left of $E$ is a small patency of the inter-ventricular septum.

(F) Tricuspid valve. 
blood can be seen at $\mathrm{A}$, between the aorta and the aneurysm of the pulmonary artery, and again at B, in the wall of the aneurysm (Fig. 3). The front of the artery and its left branch were infiltrated with blood extending into the root of the left lung.

About one inch above the valve was a linear split (Fig. $4 \mathrm{C}$ ), two inches in length, extending through the intimal coat and the medial coat and at one point through to the pericardium ; elsewhere the adventitial coat remained thin film like tissue-paper.

Above the split the wall of the artery was dissected between the media and adventitia well into the root of the left lung, and this is shown in Fig. 4 (A and $B)$.

Both the ventricles were somewhat enlarged, and their walls were thickened, while immediately below the pulmonary orifice was a small inter-ventricular communication (Fig. $4 \mathrm{E}$ ). The aorta was possibly slightly smaller than normal for the age.

The pulmonary valve was bicuspid and very large (Fig. 4 D), the cusps being quite soft and of normal texture. The aortic, mitral, and tricuspid valves were normal.

The auricles were not noticeably abnormal and the inter-auricular septum was intact. The myocardium appeared normal.

\section{Summary}

A case is reported in which an aneurysmal dilatation of the pulmonary artery, due to a congenital defect, led to sudden death from rupture of the walls of the artery, the rupture also producing some degree of dissection of the coats of the artery. 